\title{
A vulnerabilidade natural e ambiental do município de Belém (PA)
}

A expansão dos centros urbanos sem planejamento e a pouca consciência ecológica dos governos municipais têm colocado em risco a qualidade ambiental aos habitantes e áreas de preservação ambiental nesta parcela do território. Nessa perspectiva, o trabalho busca analisar a vulnerabilidade ambiental e a vulnerabilidade natural do município de Belém (PA), com o objetivo de identificar as áreas mais vulneráveis pelas intervenções antrópicas e as potencialidades dos sistemas ambientais, baseada na abordagem da ecodinâmica dos ambientes. A metodologia utiliza os Sistemas de Informações Geográficas na elaboração e integração dos mapas temáticos de geologia, geomorfologia, pedologia, cobertura vegetal e uso do solo, tendo como produto final mapas de vulnerabilidade ambiental e natural do município. Com isso, constatou-se pontos de ocorrência de áreas com alto nível de vulnerabilidade nas ilhas fluviais, devido a ocorrência de desmoronamentos em suas margens. Porém, apesar de este processo erosivo ser um fator natural, sua incidência é intensificada nos locais onde a infraestrutura urbana é precária e pelo uso indevido das formas desse relevo. Como conclusões, mostrou-se os pontos focais de maior vulnerabilidade. Entretanto, cabe ao poder público em parceria com a comunidade acadêmica e a sociedade civil discutir e buscar medidas de prevenção a possíveis desastres ambientais.

Palavras-chave: Vulnerabilidade natural; Vulnerabilidade ambiental; SIG; Município de Belém.

\section{The natural and environmental vulnerability of the municipality of Belém (PA)}

\begin{abstract}
The expansion of unplanned urban centers and the poor ecological awareness of municipal governments have endangered the environmental quality of the inhabitants and areas of environmental preservation in this part of the territory. From this perspective, the paper seeks to analyze the environmental vulnerability and the natural vulnerability of the municipality of Belém (PA), with the objective of identifying the most vulnerable areas by anthropic interventions and the potentialities of environmental systems, based on the approach of environment ecodynamics. The methodology uses Geographic Information Systems in the elaboration and integration of thematic maps of geology, geomorphology, pedology, vegetation cover and land use, having as a final product maps of environmental and natural vulnerability of the municipality. Thus, it was found points of occurrence of areas with high level of vulnerability in the fluvial islands, due to the occurrence of landslides in their banks. However, although this erosion process is a natural factor, its incidence is intensified in places where the urban infrastructure is precarious and by the misuse of the forms of this relief. As conclusions, the focal points of greater vulnerability were shown. However, it is up to the government in partnership with the academic community and civil society to discuss and seek measures to prevent possible environmental disasters.
\end{abstract}

Keywords: Natural vulnerability; Environmental vulnerability; GIS; Municipality of Belém.

Topic: Desenvolvimento, Sustentabilidade e Meio Ambiente

Reviewed anonymously in the process of blind peer.
Received: 10/01/2019

Approved: 17/04/2019
Sérgio Luis Cardoso Serrão (it)

Instituição de Ensino Superior, País

http://lattes.cnpq.br/7255962059886608

http://orcid.org/0000-0002-0803-2627

seuserrao@gmail.com

Leoni de Souza Belato (i)

Instituto Tecnológico Vale, Brasil

http://lattes.cnpq.br/7063630868527586

http://orcid.org/0000-0002-9230-2246

leonibelato@gmail.com

Rafael Pompeu Dias

Universidade Federal do Oeste do Pará, Brasi

http://lattes.cnpq.br/5061243034932992

rafaelp.dias@yahoo.com.br

\section{Referencing this:}

SERRÃO, S. L. C.; BELATO, L. S.; DIAS, R. P.. A vulnerabilidade natural e ambiental do município de Belém (PA). Nature and Conservation, v.12, n.1, p.36-45, 2019. DOI: http://doi.org/10.6008/CBPC23182881.2019.001.0004 


\section{INTRODUÇÃO}

Para o mapeamento da vulnerabilidade, os aspectos físicos e humanos são condicionantes que devem ser investigados (ALMEIDA et al., 2010). Como alguns dos parâmetros físicos relevantes ao estudo da vulnerabilidade, tem-se a degradação e erosão do solo causados pela intervenção entre o uso, vegetação e forças erosivas (erosividade, escoamento superficial e subsuperficial e energia solar); e como parâmetros humanos, estão os elementos sociais atrelados à problemática. Associando-se, portanto, o conceito de vulnerabilidade a maior ou menor fragilidade de um determinado ambiente.

O debate em torno do conceito de vulnerabilidade vem tomando força, e nas últimas décadas cada vez mais multidisciplinar, pois a vulnerabilidade pode ser natural, ambiental, social e socioambiental, estando presente nas mais diversas áreas do conhecimento. Para este estudo, as dimensões da vulnerabilidade a serem investigadas com propriedade, serão a natural e a ambiental.

Para os pesquisadores das geociências, o termo vulnerabilidade natural se caracteriza como o menor ou maior nível de estabilidade/instabilidade dos elementos bióticos e físicos, juntamente com a dinâmica, intensidade e magnitude dos processos morfogênicos, pedogênicos e de fitossucessão, que atuam em cada unidade ecodinâmica (TRICART, 1977; GRIGIO, 2003). Por outro lado, a vulnerabilidade ambiental relaciona a capacidade de resposta do ambiente aos efeitos que são provocados adversamente por ações antropogênicas, variando conforme suas características humanas e naturais, que afetam direto ou indiretamente a estabilidade do meio, assim como sua qualidade ambiental (TAGLIANI, 2003; SANTOS et al., 2007).

Desta forma, o mapeamento da vulnerabilidade em determinado território, possibilita a identificação de áreas suscetíveis a possíveis impactos ambientais, tornando-se uma ferramenta importante ao planejamento ambiental e ordenamento territorial. A representação cartográfica da vulnerabilidade aos processos erosivos, ou poluidores, ou o zoneamento por graus de riscos facilitam a compreensão da geografia dos impactos ambientais, relacionados à estrutura social dos diferentes ambientes urbanos, cujas pressões demográficas sobre a ocupação dos espaços afetam diretamente os fluxos de matérias e energias desses ambientes (COELHO, 2010).

Para ocupação de uma área, devem ser analisadas e complementadas informações através de estudos sobre a dinâmica ambiental. Estas análises ambientais devem servir de base para as políticas públicas (planos, programas e projetos), existentes nas diversas instituições e agências governamentais, nos centros de ensino e pesquisa, no setor privado e nas organizações da sociedade civil (ALMEIDA et al., 2010).

Belém, área objeto do presente estudo, situa-se na região norte do país, tem uma população de 1.485.732 habitantes, ocupando 1.059,458km² (figura 1). É o município mais populoso do estado do Pará. Trata-se de uma área contornada pelo Estuário Guajarino, onde se tem uma caraterística geográfica peculiar: o fato de ser uma cidade influenciada por rios, igarapés, baías e bacias hidrográficas de grandes dimensões, o crescimento da cidade não foi acompanhado de um planejamento urbano adequado, principalmente levando em consideração a vasta rede hidrográfica e a vegetação que a cidade possui (DIAS, 2016). 


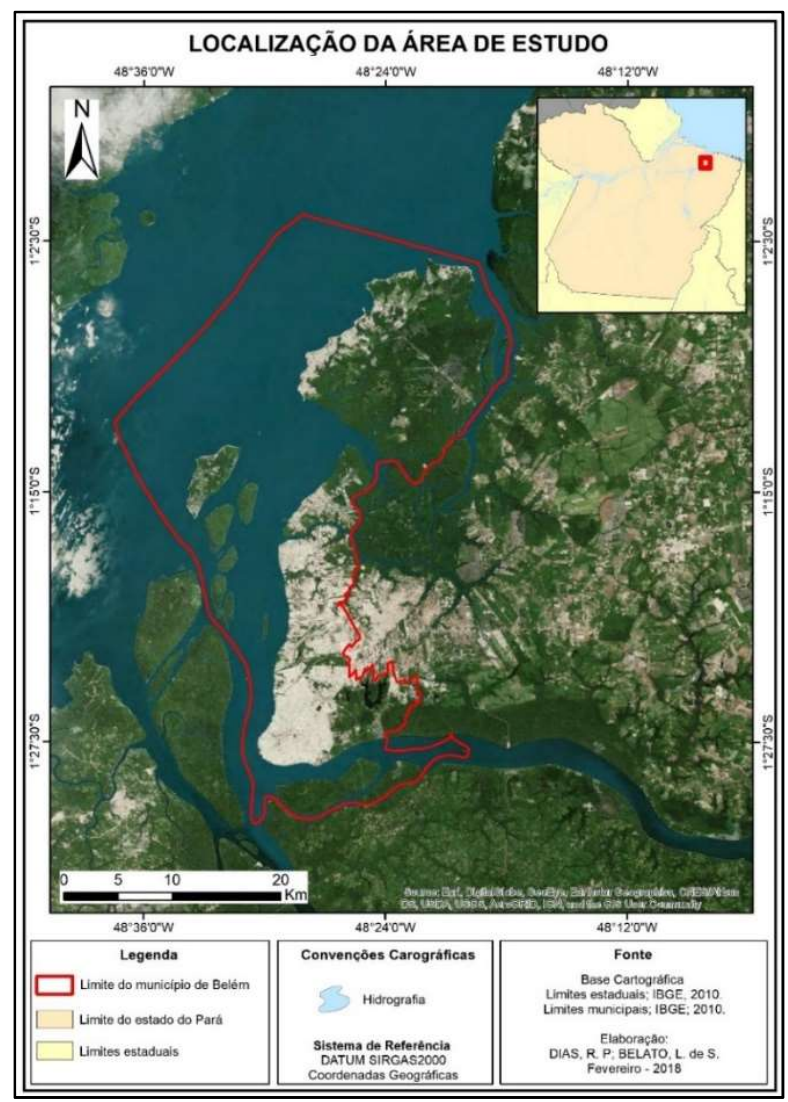

Figura 1: Localização do município de Belém (PA).

Com a intensificação do processo de urbanização do município de Belém, tem ocorrido sérios problemas de ordem ambiental e social para as pessoas que moram em seu sítio urbano. No município de Belém, na área urbana, a produção desigual do espaço tem gerado grandes perdas na cobertura vegetal, as áreas verdes estão diminuindo em função do processo de verticalização acentuado nas últimas décadas. O crescimento horizontal da metrópole, que tomou força na década de 80 , ocorreu seguindo os eixos rodoviários tais como a Rodovia Arthur Bernardes e Augusto Montenegro que liga o centro de Belém ao Distrito de Icoaraci, e levou a retração significativa da cobertura de seu verde urbano (LUZ, 2015).

O objetivo principal dessa pesquisa é identificar e analisar as áreas que possuem uma maior vulnerabilidade natural e ambiental no município de Belém, a partir da relação dos elementos físicos e bióticos e de suas ecodinâmicas, que definem as limitações ambientais às intervenções antrópicas. Nesse sentido, as informações resultantes da correlação entre esses aspectos constituirão uma importante base de dados, que poderá ser utilizada para o ordenamento territorial urbano pautado nas diretrizes do desenvolvimento sustentável.

As unidades geológicas de Belém são representadas pelos Sedimentos Quaternários, Formações Barreiras e Formação Pós-Barreiras. A deposição dessas unidades foi particularmente controlada pela formação e reativação de falhas normais e transcorrentes (COSTA et al., 1996), como também pelas mudanças eustáticas e climáticas que geraram flutuações ao nível do mar (ROSETTI, 2001). É possível caracterizar a região de Belém como possuidora de unidades litoestratigráficas, argilo-arenosas e arenoargilosas caracterizadas como sendo de épocas mioceno-pliocênicas oriundas de fatores tectono-estruturais 
(falhas normais e transcorrentes) (IGREJA et al., 1990, ROSSETTI, 2001). O nível Belém-Marajó é uma planície suave, com altura média de 6 a 15 metros sobre o nível médio das marés.

O município de Belém se caracteriza ainda por apresentar temperaturas sempre altas, forte convecção, ar instável e alta umidade do ar favorecendo a formação de nuvens convectivas. As temperaturas altas estão associadas ao elevado potencial de radiação solar incidente, embora grande parte da energia seja convertida em calor latente de evaporação e outra parte convertida em calor sensível que é destinado ao aquecimento do ar. A forte convecção, a instabilidade e a alta umidade do ar favorecem a formação de nuvens convectivas, dando origem a uma grande incidência de precipitação na forma de pancadas, principalmente à tarde, situação característica de regime de chuva do tipo continental (NECHET, 1997).

\section{MATERIAIS E MÉTODOS}

Para estudar a vulnerabilidade natural e ambiental do município de Belém, optou-se pela aplicação da análise ecodinâmica fundamentada na compreensão de estabilidade/instabilidade ambiental (TRICART, 1977). Nesse sentido, definem-se unidades ecodinâmicas a partir da análise dos processos de pedológicos e morfológicos. Essas unidades correspondem a uma esfera natural de território a funcionar com um sistema e, dessa maneira, manter diversos vínculos entre os componentes em um fluxo de energia e matéria que o distingue.

Para Tricart (1992), o entendimento sobre o comportamento do meio ambiente perpassa pelo estudo da morfodinâmica, método importante para a utilização racional dos recursos naturais e análise de riscos aos ambientes, quando susceptíveis às intervenções antropogênicas. Para a organização territorial é fundamental a aplicação da análise ecodinâmica, para elucidar a dinâmicidade das ações humanas empregadas em determinado sistema ambiental, que por sua vez gera uma resposta específica à ação. Dessa maneira, permitindo o planejamento ambiental das ações de intervenção do homem sobre os sistemas ambientais, otimizando a utilização dos recursos naturais e diminuindo os processos socioeconômicos e culturais das sociedades modernas (ROSS, 2009).

Os mapas de vulnerabilidade natural e ambiental de Belém foram elaborados a partir da integração dos índices de vulnerabilidade de cada atributo dos meios físico, biótico e das formas de uso do solo. Gerando em um primeiro momento os mapas de geologia, pedologia, vegetação e geomorfologia, voltados a elaboração do mapa de vulnerabilidade natural. Em um segundo momento, o mapa de uso do solo foi sobreposto ao mapa de vulnerabilidade natural, resultando em um mapa de vulnerabilidade ambiental (figura 2). Os valores do grau de vulnerabilidade de cada atributo foram adaptados da metodologia empregada por Costa et al. (2006) e Grigio (2003). Utilizou-se na determinação do grau de vulnerabilidade de cada atributo a relação de predomínio entre os processos erosivos e pedogenéticos.

Em cada classe, o grau de vulnerabilidade foi distribuído em uma escala de 1 a 3, com intervalos de 0,5. Com predominância da pedogênese, vulnerabilidade muito baixa, atribuiu-se o valor de 1 . Com o aumento da influência dos processos erosivos, o grau de vulnerabilidade aumenta até atingir o valor máximo, sendo 3, representando ambientes de vulnerabilidade muito alta (COSTA et al., 2006). A tabela 1 apresenta 
o índice de vulnerabilidade de cada atributo ambiental. Com isso, foram formadas cinco classes de vulnerabilidade com intervalos iguais. A tabela 2 representa as classes de vulnerabilidades natural e ambiental, formadas pelos cruzamentos dos diversos atributos analisados.

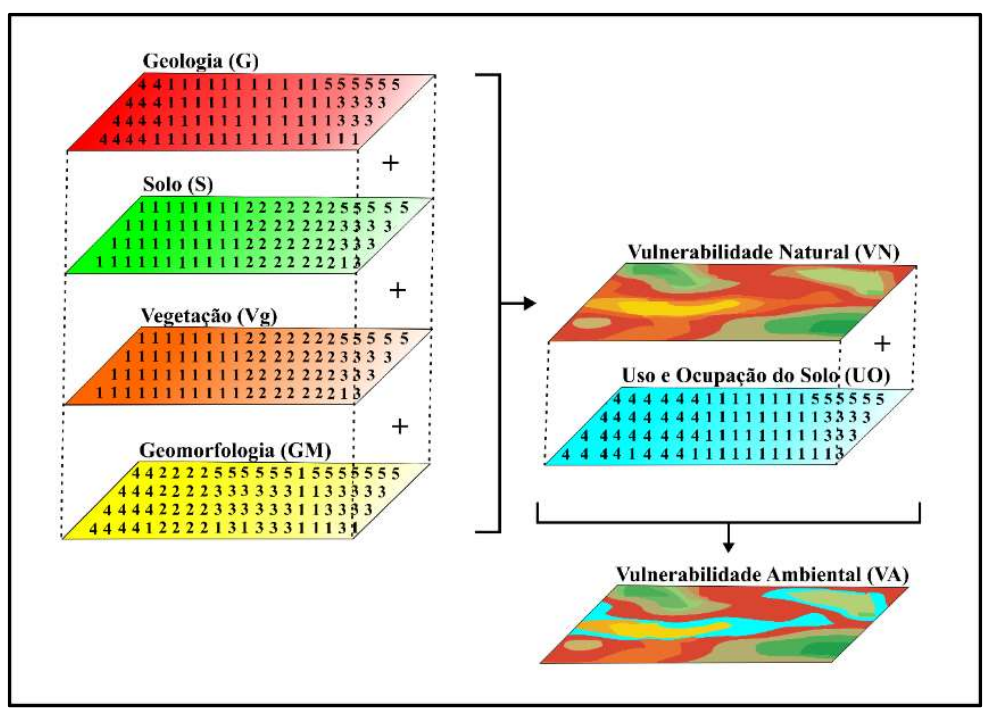

Figura 2: Roteiro para elaboração dos mapas de vulnerabilidade natural e ambiental. Fonte: Costa et al. (2006).

Tabela 1: Índice de vulnerabilidade natural e ambiental dos elementos da paisagem.

\begin{tabular}{|c|c|}
\hline Atributos Ambientais & Índice de Vulnerabilidade Natural e Ambiental \\
\hline \multicolumn{2}{|c|}{ Cobertura Vegetal } \\
\hline Floresta Ombrófila Densa Aluvial & 1 \\
\hline Floresta Ombrófila Densa Aluvial Com Dossez Uniformes & 1 \\
\hline Floresta Ombrófila Densa das Terras Baixas & 1 \\
\hline \multicolumn{2}{|l|}{ Pedologia } \\
\hline Corpos d'água continentais & 1,5 \\
\hline Espodossolo Ferrihumilúvico Hidromórfico & 2 \\
\hline Plintossolo Pétrico Concrecionário & 3 \\
\hline Gleissolo Háplico tb Eutrófico & 3 \\
\hline Gleissolo Háplico tb Distrófico & 3 \\
\hline Latossolo Amarelo Distrófico & 1 \\
\hline \multicolumn{2}{|l|}{ Geologia } \\
\hline Corpos D'agua continentais & 3 \\
\hline Aluviões Holocênicos & 3 \\
\hline Formação Barreiras & 2 \\
\hline Cobertura Detrito-Laterítica Neopleistocênica & 1 \\
\hline Cobertura Sedimetar do Baixo Tocantins & 1,5 \\
\hline Depósitos de Pantanos e Mangês Holocênicos & 3 \\
\hline \multicolumn{2}{|l|}{ Geomorfologia } \\
\hline Massa d'água Continental & 1,5 \\
\hline Planícies Fluviomarinhas & 3 \\
\hline Tabuleiros Costeiros & 3 \\
\hline \multicolumn{2}{|l|}{ Uso e ocupação } \\
\hline Área Não Observada & 1 \\
\hline Área Urbana & 3 \\
\hline Floresta & 1 \\
\hline Hidrografia & 1 \\
\hline Mosaico de Ocupações & 2,5 \\
\hline Não Floresta & 2,5 \\
\hline Outros & 2,5 \\
\hline Pasto com Solo Exposto & 3 \\
\hline Pasto Limpo & 3 \\
\hline Pasto Sujo & 3 \\
\hline Regeneração Com Pasto & 1,5 \\
\hline Vegetação Secundária & 1,5 \\
\hline
\end{tabular}

Fonte: Costa et al. (2006). 
Tabela 2: Classes de vulnerabilidades natural e ambiental.

\begin{tabular}{|c|c|}
\hline Classes & Médias \\
\hline Muito Baixa & $0-0,85$ \\
\hline Baixa & $0,86-1,07$ \\
\hline Média & $1,08-1,40$ \\
\hline Alta & $1,41-1,85$ \\
\hline Muito Alta & $1,86-3$ \\
\hline
\end{tabular}

Para a confecção dos mapas foi utilizado o software Arcgis 10.5. Esse programa apresenta uma plataforma de SIG (Sistema de Informações Geográficas), possibilitando a manipulação de feições espaciais georreferenciadas associadas a um banco de dados com as informações analíticas, além de permitir o cruzamento entre os mapas produzidos.

Foram utilizados arquivos vetoriais em formato shapefile de vegetação, pedologia, geomorfologia e geologia, do ano de 2010, obtidos junto ao site do IBGE (Instituto Brasileiro de Geografia e Estatística), e os arquivos do mapeamento do uso do solo do projeto TERRACLASS, do ano de 2014, Orbita 223, Ponto 064, obtidos junto ao site do INPE (Instituto Nacional de Pesquisas Espaciais), os dados foram cruzados e transformados em arquivos de formato de saída RASTER, sua finalização se deu com a inclusão dos elementos cartográficos obrigatórios (fonte, legenda, orientação e escala).

\section{RESULTADOS E DISCUSSÃO}

\section{Vulnerabilidade natural}

Os graus de vulnerabilidade natural podem ser visualizados na figura 3, onde as unidades mapeadas variam da classe muito baixa a muito alta, demonstrando também a distribuição das classes de vulnerabilidade natural em termos percentuais e de área $\left(\mathrm{km}^{2}\right)$. O mapa de vulnerabilidade natural é uma importante ferramenta para auxiliar a tomada de decisão dos gestores públicos, ao indicar espacialmente os ambientes tidos como mais vulneráveis. Essa ferramenta possibilitou, neste estudo, uma melhor visualização das repostas do ambiente analisado às intervenções antrópicas.

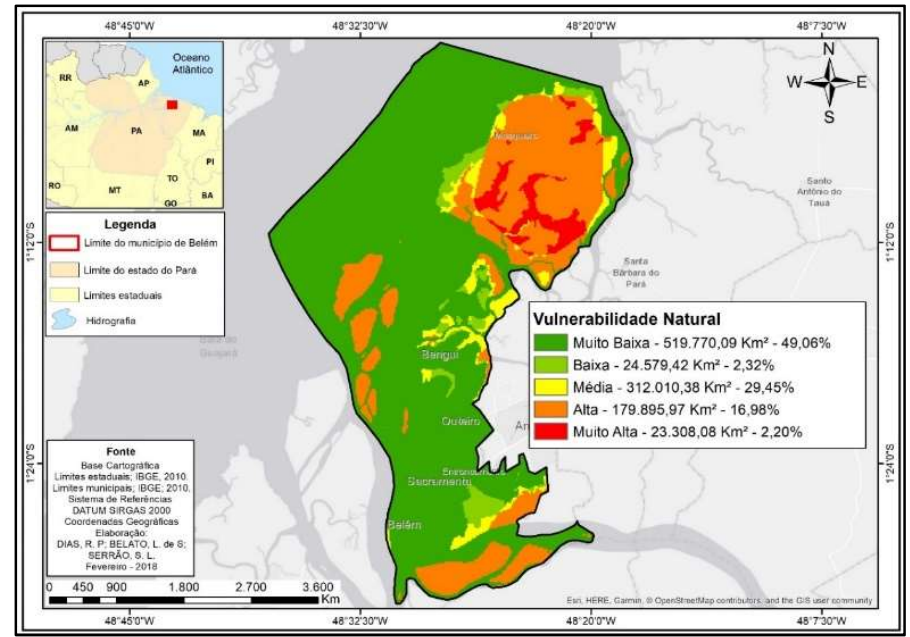

Figura 3: Mapa de vulnerabilidade natural do município de Belém (PA).

A vulnerabilidade muito baixa é a maior unidade mapeada, abrangendo aproximadamente $49,06 \%$ do território do município. Essa área corresponde a uma região do município influenciada por rios, igarapés, 
baías, e bacias hidrográficas de grandes dimensões e são representadas por restos da formação Barreiras e terrenos do Quaternário. Refletindo a litologia, suas formas de relevo caracterizam-se pelos baixos platôs e planícies litorâneas, fazendo parte neste contexto, junto com áreas limítrofes, na unidade morfoestrutural Planalto Rebaixado do Amazonas (Baixo Amazonas).

Essas características tendem a elevar a estabilidade, decorrente das características dos elementos da paisagem. Os solos do município têm características: Latossolo Amarelo Distrófico; Gleissolo eutrófico e distrófico. A vegetação dos mangues acompanha as porções fluviais e semilitorâneas do setor estuarino, enquanto a Floresta Ombrófila domina os tratos marginais dos cursos d'água e as baixadas, onde prevalecem formações herbáceas, subarbustiva e arbustiva. Nesta unidade, deve-se priorizar as atividades de conservação, tendo em vista que são ambientes de relevante interesse para a qualidade ambiental e paisagístico do município de Belém.

A vulnerabilidade baixa envolve uma das menores porções do município, com 2,32\%. É formada pela mesma geologia e geomorfologia da unidade anterior. As unidades de baixa e média vulnerabilidade são as melhores áreas para ocupação e intervenção ambiental, desde que sejam respeitados os preceitos das legislações ambientais e urbanísticas e se adotem práticas conservacionistas.

A vulnerabilidade média, com pouco mais de $29 \%$ de área, encontra-se em unidades onde a ecodinâmica é de alta dinamicidade natural, devido à ação constante dos processos morfogênicos. Tais áreas localizam-se principalmente sob locais urbanizados com Latossolo Amarelo Distrófico. Também é encontrada próxima aos cursos d'água, onde há solos mais vulneráveis ou ausência de vegetação. Essas áreas estão abaixo da cota de 4 metros, sofrendo influência das marés altas e tendo dificuldade no escoamento nas águas da chuva dentro da área urbana, sendo chamadas 'baixadas de Belém'.

A vulnerabilidade alta, com mais de $16 \%$ de área, é constituída pelos Tabuleiros de Aluviões Holocênicos, mas apresenta solos e vegetação limitantes. Assim, foram identificados Gleissolo Háplico Tb Eutrófico e Distrófico e Latossolo Amarelo Distrófico associados a cobertura vegetal de floresta secundária ou capoeiras que substituíram a antiga floresta densa dos baixos platôs, da qual testemunhos ainda são encontrados em Mosqueiro, Caratateua e áreas adjacentes marcadas pela grande concentração de ilhas. Essa destaca-se por ser Área de Proteção Ambiental, a qual é essencialmente formada por floresta de várzea, um dos principais tipos de florestas inundáveis amazônicas.

A vulnerabilidade muito alta, com uma porcentagem pouco representativa $(2,20 \%)$, encontra-se nos setores onde os processos morfogênicos atuam mais intensamente. São representados pela planície litorânea urbanizada e planícies fluviais, lacustres e fluviomarinhas degradadas. Observa-se que mesmo em estado natural essa unidade apresentaria vulnerabilidade natural muito alta, e devido aos processos de degradação, este fator é ampliado, colocando em situação vulnerável a população deste ambiente.

Devido às características naturais, de relevância ambiental, e ao elevado estágio de degradação nesta unidade, bem como na anterior, devem prevalecer medidas de conservação e recuperação ambiental dessas áreas, havendo inclusive a necessidade de intervenções. Deve-se respeitar a legislação ambiental pertinente, 
incentivar o emprego de tecnologias menos impactantes, promover a aplicação dos planos de controle e monitoramento ambiental e a adoção de medidas compensatórias e de práticas ambientalmente corretas.

\section{Vulnerabilidade ambiental}

Analisando os impactos no mapa de vulnerabilidade ambiental - nos termos do grau de suscetibilidade a situações de risco ambiental - podem ser observadas as possíveis respostas do meio às intervenções, que variam de acordo com as características naturais e o uso do solo. A figura 4 apresenta também a distribuição percentual e área da vulnerabilidade ambiental.

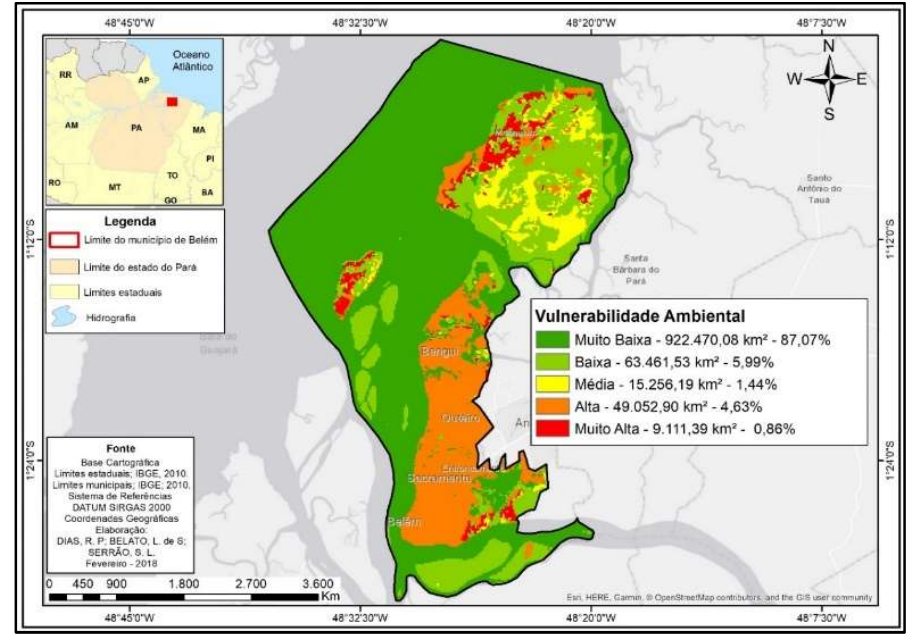

Figura 4: Mapa de vulnerabilidade ambiental do município de Belém (PA).

A vulnerabilidade ambiental muito baixa no município de Belém, corresponde à maior unidade mapeada do território estudado, que abrange aproximadamente $87 \%$ da área total. Está presente em áreas associadas a ambientes com corpos d'agua ou recobertas por vegetação. São áreas de melhor qualidade ambiental do município e as mais promissoras para a intervenção antrópica, uma vez que suas características proporcionam menores situações de risco ambiental, resguardadas as limitações e a legislação ambiental pertinente. A vulnerabilidade muito baixa também é observada em outros pontos isolados pela cidade, chegando à ilha de Mosqueiro e outras ilhas dentro do limite municipal de Belém.

A vulnerabilidade baixa se estende por uma área de aproximadamente $6 \%$ do município. É formada por ambientes associados às áreas com presença de vegetação. Localiza-se principalmente no bairro CurióUtinga, onde estão situados os lagos Bolonha e Água Preta, que abastecem a cidade e integram a Unidade de Conservação Estatual Parque Estadual do Utinga. O Parque apresenta florestas de terra firme que ocorrem sobre solo argiloso e úmido nas regiões internas e altas, vegetação de palmeiras, ervas, epífitas, lianas, arvoredos e árvores. Às margens dos Lagos Bolonha e Água Preta há ocorrência de florestas de igapó, que compõem sua vegetação em áreas de terreno baixo e úmido, há também a presença de floresta ombrófila densa, distribuída por diversas áreas ao longo do Parque. Apesar de apresentar vulnerabilidade baixa, essa unidade necessita de adoção de medidas de recuperação, controle e monitoramento ambiental.

A vulnerabilidade média encontra-se em apenas $1,44 \%$ da área total pesquisada e distribui-se em manchas isoladas no interior do município e em suas ilhas, correspondendo a mosaicos, ora compostos por 
ambientes com vulnerabilidade natural muito alta associados a áreas com infraestrutura consolidada, ora constituindo ambientes de vulnerabilidade alta associados às áreas de infraestrutura precária, ou mesmo vulnerabilidade média com infraestrutura mediana. Devido às características diferenciadas entre os diversos setores dessa unidade, a tomada de decisões deve ser realizada em escala mais detalhada e levando em consideração a especificidade ambiental de cada setor.

A vulnerabilidade alta, localiza-se sobre a planície urbanizada de vulnerabilidade natural média e baixa, ocupando áreas com infraestrutura consolidada, como os bairros da Sacramenta, Entroncamento, Outeiro, Bengui, entre outros. Também foi identificada em áreas com planícies fluviolacustre e fluviomarinhas vegetadas situadas nas ilhas dentro do limite municipal.

A vulnerabilidade muito alta, corresponde a todas as áreas que apresentam infraestrutura precária e ambiente de elevada vulnerabilidade natural, principalmente nas planícies fluviais da ilha de Cotijuba e Mosqueiro, e em áreas urbanas que sofrem influências das marés altas e tendo dificuldade no escoamento das águas da chuva, com destaque aos bairros do Guamá e Terra firme, correspondendo a áreas de risco ambiental, de tal forma que a população habitante está muito suscetível à dinamicidade destes ambientes.

\section{CONSIDERAÇÕES FINAIS}

Nesse estudo, os mapas produzidos - nos termos do grau de suscetibilidade a situações de risco ambiental - foram capazes de apontar as possíveis respostas do meio às intervenções humanas, que variaram de acordo com as características naturais e o uso do solo. De acordo com os resultados obtidos, constatouse que o município de Belém apresenta, predominantemente, vulnerabilidade natural muito baixa e mediana decorrente das formações Barreiras e Cobertura Detrito-Laterítica Neopleistocênica nos tabuleiros costeiros, que são mais estáveis.

As áreas naturalmente mais vulneráveis são as planícies fluviolacustre, fluviomarinhas e litorâneas. Esses sistemas são fundamentais para a manutenção do equilíbrio ambiental da cidade, devendo prevalecer medidas de proteção e recuperação associadas à implantação de infraestrutura urbana adaptada às vulnerabilidades naturais existentes. A vulnerabilidade muito baixa corresponde a maior área do município, devendo haver medidas de conservação ambiental, pois estas áreas são fundamentais para a qualidade ambiental da cidade.

Quanto à vulnerabilidade ambiental, conclui-se que a maior parte do município possui vulnerabilidade muito baixas e baixas. A classe alta representa ambientes de vulnerabilidade natural baixa com infraestrutura consolidada ou pontos isolados de áreas de infraestrutura precária sobre ambientes mediamente vulneráveis. A classe muito alta é constituída por ambientes de vulnerabilidade natural alta e muito alta com infraestrutura precária, ocupadas por populações socialmente vulneráveis e suscetíveis aos riscos ambientais. As áreas de vulnerabilidade ambiental muito baixa correspondem aos setores de tabuleiros vegetados e compostos por uma grande massa d'água continental.

A realização deste trabalho somente foi possível devido ao uso de SIG que possibilitaram a espacialização dos elementos ambientais analisados, pois percebe-se que a situação é preocupante, quando 
se considera o tamanho do município, a velocidade do desmatamento, a crescente ocupação urbana e a dilapidação das florestas remanescentes, restando florestas pobres, com funções e estruturas alteradas.

\section{REFERÊNCIAS}

AB'SÁBER, A. N.. Paleoclima e paleoecologia da Amazônia brasileira: estudo introdutório. In: AB'SÁBER, A. N..

Amazônia: do discurso à práxis. 2 ed. São Paulo: EDUSP, 2004.

ALMEIDA, F. G.; GUERRA, A. J. T.. Erosão dos Solos e Impactos Ambientais na Cidade de Sorriso (Mato Grosso). In: GUERRA, A. J. T.; CUNHA, S. B.. Impactos Ambientais Urbanos no Brasil. 6 ed. Rio de Janeiro: Bertrand Brasil, 2010. p.253-274.

COELHO, M. C. N.. Impactos Ambientais em Áreas Urbanas. In: GUERRA, A. J. T.; CUNHA, S. B.. Impactos Ambientais Urbanos no Brasil. 6 ed. Rio de Janeiro: Bertrand Brasil, 2010.

COSTA, J. L.; ALMEIDA, H. G. G.; RICCI, P. S. F. Metamorfismo e divisão tectonoestratigráfica do Grupo Gurupi no nordeste do Pará e noroeste do Maranhão: In: SIMPÓSIO DE GEOLOGIA DA AMAZÔNIA, 5. Anais. Belém: SBG, 1996.

DIAS, R. P.. Análise hidrogeomorfologica e uso e ocupação do solo da bacia hidrografica urbana de armas-reduto, Belém-PA. Monografia (Graduação em Geografia) Universidade Federal do Pará, Belém, 2016.

FIGUEIRÊDO, M. C. B.. Avaliação da Vulnerabilidade Ambiental de Reservatórios à Eutrofização. Revista Engenharia Sanitária e Ambiental, Rio de Janeiro, v.12, n.4, p.399-409, 2007.

GUERRA, A. J. T.; MARÇAL, M. S.. Geomofologia ambiental. Rio de Janeiro: Bertrand Brasil, 2006.
IBGE. Instituto Brasileiro de Geografia e Estatística. Estimativas da População Residente no Brasil. Brasília: IBGE, 2016.

IGREJA, H. S.; BORGES, M. S.; ALVES, R. J.; COSTA JÚNIOR, P. S.; COSTA, J. B. S.. Estudos neotectônicos nas ilhas de Outeiro e Mosqueiro - Nordeste do Estado do Pará. In: CONGRESSO BRASILEIRO DE GEOLOGIA, 36. Anais. Natal: SBG, 1990.

LUZ, L. M.; ARAÚJO M. L.; RODRIGUES, J. E. C.. Estudo das áreas verdes e índice de cobertura vegetal do Distrito Administrativo de Icoaraci - DAICO, Belém-PA. GEONORTE, v.2, n.4, p.1454-1463, 2012.

NECHET, D.. Variabilidade diurna de precipitação em BelémPA: aplicação em planejamento a médio e longo prazo. Boletim Climatológico, Presidente Prudente, v.2, n.3, p.223227, 1997.

ROSSETTI, D. F.; GÓES, A. M.; ARAl, M.. A passagem AptianoAlbiano na Bacia do Grajaú, Maranhão. In: ROSSETTI, D. F.; GÓES, A. M.; TRUCKENBRODT, W.. O Cretáceo da Bacia de São Luís-Grajaú. Belém: EDMPEG, 2001. p.101-118.

SANTOS, R. F.; CALDEYRO, V. S.. Vulnerabilidade Ambiental: desastres ambientais ou fenômenos induzidos?. Brasília: MMA, 2007.

TAGLIANI, C. R. A.. Técnicas para avaliação da vulnerabilidade ambiental de ambientes costeiros utilizando um sistema geográfico de informações. In: SIMPÓSIO BRASILEIRO DE SENSORIAMENTO REMOTO, 11. Anais. Belo Horizonte: INPE, 2003.

TRICART, J.. Ecodinâmica. Rio de Janeiro: IBGE, 1977.

A CBPC - Companhia Brasileira de Produção Científica (CNPJ: 11.221.422/0001-03) detém os direitos materiais desta publicação. Os direitos referem-se à publicação do trabalho em qualquer parte do mundo, incluindo os direitos às renovações, expansões e disseminações da contribuição, bem como outros direitos subsidiários. Todos os trabalhos publicados eletronicamente poderão posteriormente ser publicados em coletâneas impressas sob coordenação da Sustenere Publishing, da Companhia Brasileira de Produção Científica e seus parceiros autorizados. Os (as) autores (as) preservam os direitos autorais, mas não têm permissão para a publicação da contribuição em outro meio, impresso ou digital, em português ou em tradução. 